\title{
STRATEGI PENGEMBAGAN BISNIS KEDAI KOPI“AI COFFEE” DI DESA PAKEMITAN KECAMATAN CIAWI KABUPATEN TASIKMALAYA
}

\author{
DEVELOPMENT STRATEGY OF "AI COFFEE" COFFEE COFFEE BUSINESS IN \\ PAKEMITAN VILLAGE, CIAWI DISTRICT, TASIKMALAYA REGENCY
}

\author{
DEDE YENI MARYANI ${ }^{1 *}$, DINI ROCHDIANI ${ }^{2}$, BUDI SETIA ${ }^{1}$ \\ ${ }^{1}$ Fakultas Pertanian Universitas Galuh \\ ${ }^{2}$ Fakultas Pertanian Universitas Padjajaran \\ *Email :dedeyeni191@gmail.com
}

\begin{abstract}
ABSTRAK
Kedai kopi merupakan tempat berkumpul dan bersantai sambil minum kopi. Salah satu kedai kopi yang berada di Desa Pakemitan Kecamatan Ciawi yaitu Kedai "AI COFFEE". Penelitian ini dilakukan pada Kedai Kopi "AI COFFEE". Tujuan dari penelitian adalah untuk mengetahui faktor internal dan eksterna dalam pengembangan Kedai Kopi AI setra menentukan strategi yang terdapat dalam pengembangan kedai kopi AI dengan menggunakan matriks faktor strategi internal/ IFAS, matriks faktor strategi eksternal/ EFAS dan matriks SWOT (Strength, Weakness, Opportunity, Treats). Jenis penelitian yang digunakan yaitu studikasus.Jenis data yang digunakan data primer dan data sekunder.Teknik penarikan sampel yang digunakan dalam penelitian ini yaitu purvosive sampling.Hasil penelitian menunjukan faktor internal yang menjadi kekuatan dan kelemahan dalam pengembangan bisnis kedai kopi "AI COFFEE" masing-masing terdapat tujuh tujuh faktor. Adapun faktor-faktor internal yang menjadi kekuatan yang dominan kedai "AI COFFEE" yaitu modal sendiri dan produk mempunyai atribut kemasan dengan skor 0,41 . Sedangkam kelemahan yang dominan yaitu masih menggunakan sistem informasi manajemen manual, jenis produk yang dihasilkan masih kurang dan kurangnya promosi dengan skor 0,28. Sedangkan faktor eksternal yang menjadi peluang dan ancaman masing-masing mempunyai lima faktor. Adapun Faktor-faktor eksternal yang menjadi peluang dominan dari kedai "AI COFFE" yaitu pangsa pasar olahan kopi masih luas, berkembangnya tren minum kopi di kalangan masyarakat dan masih banyak jenis produk kopi yang bisa diproduksi dengan skor 0,57. Sedangkan yang menjadi ancaman dominan kedai kopi "AI COFFEE" yaitu persaingan usaha sejenis dengan skor 0,57 . Straegi pengembangan yang tepat untuk pengembangan bisnis "AI COFFE" yaitu Strategi S-O yang diperoleh dari matriks SWOT.
\end{abstract}

Kata Kunci: Kopi, Strategi, IFAS, EFAS, SWOT.

\begin{abstract}
A coffee shop is a place to gather and relax while drinking coffee. One of the coffee shops in Pakemitan Village, Ciawi District, is the "AI COFFEE" shop. This research was conducted at the "AI COFFEE" Coffee Shop. The purpose of the study was to determine internal and external factors in the development of AI Setra Coffee Shop to determine the strategies contained in the AI coffee shop development using the internal strategy factor matrix / IFAS, the external strategy factor matrix / EFAS and the SWOT matrix (Strength, Weakness, Opportunity, Treats). This type of research is a case study. The types of data used are primary data and secondary data. The sampling technique used in this study was purposive sampling. The results showed that there are seven internal factors which are the strengths and weaknesses in the development of the coffee shop business "AI COFFEE". The internal factors that become the dominant strength of the "AI COFFEE" shop are equity and the product has packaging attributes with a score of 0.41. While the dominant weaknesses are still using manual management information systems, the types of products produced are still lacking and lack of promotion with a score of 0.28. Meanwhile, the external factors which become opportunities and threats each have five factors. The external factors that become the dominant opportunity for the "AI COFFE" shop are the still wide market share of processed coffee, the growing trend of drinking
\end{abstract}


coffee among the community and there are still many types of coffee products that can be produced with a score of 0.57. Meanwhile, the dominant threat to the coffee shop "AI COFFEE" is similar business competition with a score of 0.57. The right development strategy for business development "AI COFFE" is the S-O Strategy obtained from the SWOT matrix.

Keywords: Coffee, Strategy, IFAS, EFAS, SWOT.

\section{PENDAHULUAN}

Rahardj (2012) mengemukakan bahwa Kopi adalah salah satu hasil komoditi perkebunan yang memiliki nilai ekonomis yang cukup tinggi diantara tanaman perkebunan lainnya dan berperan penting sebagai sumber devisa Negara. Kopi tidak hanya berperan penting sebagai sumber devisa melainkan juga merupakan sumber penghasilan bagi tidak kurang dari satu setengah juta jiwa petani kopi di Indonesia. Kopi telah menjadi produk minuman yang digemari oleh berbagai kalangan masyarakat, mulai dari petani, buruh, mahasiswa hingga elit-elit politik.Dalam kehidupan keseharian selain menyajikan rasa nikmat yang khas, kopi juga menjadi salah satu minuman yang cocok untuk aktivitas manusia mulai dari sarapan, bersantai, bekerja, istirahat, berdiskusi, atau sekedar berbincang-bincang dengan teman selalu di damping dengan kopi.Tidak bisa dipungkiri bahwa kopi telah menjadi bagian dari hidup manusia saat ini dan sejak dulu kala.

Di daerah Kabupaten Tasikmalaya telah banyak berdiri kedai kopi yang merupakan tempat berkumpul dan bersantai sambil minum kopi. Salah satu kedai kopi di Kabupaten Tasikmalaya berada di Desa Pakemitan Kecamatan Ciawi hususnya terdapat Kedai Kopi “AI COFFEE" merupakan sebuah usaha kecil menengah (UKM) yang bergerak dibidang pengolahan kopi. "AI COFFEE" merupakan kedai kopi yang pertama berdiri di Desa Pakemitan Kecamatan Ciawi.“AI COFFEE” memberikan jasa pelayanan penjualan pengolahan kopi dengan beraneka menu olahan kopi.Dalam kegiatan produksi "AI COFFEE" menggunakan teknologi yang sudah modern namun kapasitas produksi masih terbatas karena permintaan konsumen yang masih kurang dan penggunaan kapasitas alat dan mesin masih berskala kecil.Dapat dilihat dari menu olahan. 
Tabel 1. Produksi Olahan Kopi Berdasarkan Menu Espreso Based berdasarkan Maret 2019-Februari 2020

\begin{tabular}{cccccc}
\hline \multirow{2}{*}{ Bulan Ke } & \multicolumn{5}{l}{ Produksi Berdasarkan Menu Espreso Based (Cup) } \\
\cline { 2 - 6 } & Long Black & AI Silegit & Capucino & Es Kopi Susu & Café Latte \\
\hline 1 & 4 & 22 & 4 & 0 & 23 \\
2 & 0 & 0 & 10 & 10 & 37 \\
3 & 0 & 0 & 6 & 0 & 53 \\
4 & 0 & 0 & 19 & 0 & 34 \\
5 & 0 & 0 & 15 & 0 & 86 \\
6 & 4 & 0 & 24 & 0 & 87 \\
7 & 6 & 0 & 6 & 0 & 45 \\
8 & 1 & 6 & 0 & 15 & 10 \\
9 & 17 & 38 & 13 & 28 & 73 \\
10 & 6 & 5 & 3 & 29 & 14 \\
11 & 0 & 5 & 0 & 6 & 7 \\
12 & 0 & 20 & 13 & 35 & 25 \\
\hline Total & $\mathbf{3 8}$ & $\mathbf{9 6}$ & $\mathbf{1 3 1}$ & $\mathbf{1 2 3}$ & $\mathbf{4 9 4}$ \\
\hline
\end{tabular}

Sumber : AI COFFEE, 2020

Berdasarkan Tabel 1. dapat dilihat bahwa produksi “AI COFFEE" selama 12 Bulan. Yaitu dari Maret 2019 - Februari 2020 menghasilkan 864 cup.

Produksi yang dihasilkan "AI COFFEE" masih terbilang kecil.Hal ini dikarenakan masih kurangnya minat konsumen dan keterbatasan alat mesin produksi.Permasalahan yang dihadapi "AI COFFEE" bukan hanya pada masalah produksi saja, melainkan masalah manajemen dan pemasaran. Permasalahan produksi yaitu kelangkaan bahan baku serta harganya tidak menentu. Perusahaan masih menggunakan sistem informasi manajemen secara manual dan masih ditemukannya tumpang tindih pekerjaan dalam kegiatan perusahaan.Pemasaran yang dilakukan "AI COFFEE" masih kurang.
Sistem pemasaran kedai kopi "AI COFFEE" dilakukan secara manual dan modern.Manualnya yaitu menggunakan selebaran pemberitahuan kepada konsumen sedangkan modernnya yaitu memanfaatkan sosial media untuk menawarkan produknya.Walaupun produk ditawarkan secara online namun promosi masih sangat kurang dan jaringan distribusi yang belum luas.

\section{METODE PENELITIAN}

\section{Tempat dan waktu penelitian}

Penelitian dilakukan pada Usaha Kedai Coffee "AI COFFE" Di Desa Pakemitan Kecamatan Ciawi Kabupaten Tasikmalaya.Penelitian berlangsung pada bulan April 2020. 


\section{Teknik Pengumpulan Data}

Jenis data yang digunakan dalam penelitian ini terdiri dari data primer dan data sekunder.

\section{Teknik Penarikan Sampel}

Teknik penarikan sampel yang digunakan dalam penelitian ini yaitu purposive sampling.Arikunto (2006) menyatakan, purvosive sampling adalah penentuan sampel dengan pertimbangan tertentu yang dipandang dapat memberikan data secara maksimal maka pemilihan kelompok subjek didasarkan atas ciri atau sifat tertentu yang dipandang mempunyai sangkut-paut yang erat dengan ciri atau sifat populasi yang sudah diketahui sebelumnya.

\section{Rancangan Analisis Data}

Suatu penelitian menunjukan bahwa kualitas perusahaan hasil dari strategi pengembangan dapat ditentukan oleh kombinasi faktor internal dan faktor eksternal. Dimana kedua faktor tersebut harus melalui pertimbangan analisis SWOT. Menurut Rangkuti (2009),analisis SWOT merupakan analisis yang digunakan untuk memperoleh formulasi strategi yang tepat dari hasil perbandingan antara faktor internal dan eksternal.

Matriks SWOT merupakan alat untuk mencocokan untuk manajer dalam mengembangkan empat tipe strategi yaitu, strategi SO (kekuatan-peluang), Strategi WO (kelemahan-peluang), strategi ST (kekuatan-ancaman), dan strategi WT (kelemahan-ancaman). Matriks SWOT menggambarkan dengan jelas bagaimana peluang dan ancaman dapat diselesaikan dengan kekuatan dan kelemahan.

\section{HASIL DAN PEMBAHASAN \\ Identifikasi faktor internal dan eksternal}

\section{Faktor Internal}

Berdasarkan hasil penelitian pada responden pengolah kopi di kedai kopi “AI COFFEE", maka diperoleh faktor-faktor internal kekuatan dan kelemahan yang mempengaruhi pengembangan kedai kopi "AI COFFEE" di Desa Pakemitan. Beberapa faktor internal yang berkaitan dengan pengembangan kedai Kopi ini, yaitu :

\section{a. Kekuatan (S)}

(1)Koordinasi internal perusahaan terlaksana dengan baik (2) Modal sendiri (3) Lokasi usaha strategis (4) Harga produk bersaing (5) Produk mempunyai atribut kemasan (6) Tenaga kerja disiplin dan memahami tugas (7) Hubungan baik dengan pelanggan.

\section{b. Kelemahan (W)}

(1) Masih menggunakan sistem informasi manajemen manual (2) Jaringan distribusi 
yang belum luas (3) Keterbatasan peralatan pengolahan kopi yang dimiliki (4) Jenis produk yang dihasilkan masih kurang (5) Terbatasnya inovasi ilmu pengetahuan dan teknologi (6) Masih kurangnya jumlah tenaga kerja (7) Kurangnya promosi

\section{Faktor Eksternal}

Beberapa faktor eksternal yang berkaitan dengan pengembangan bisnis kedai kopi yaitu:

\section{a. Peluang (O)}

(1) Pangsa pasar olahan kopi masih luas

(2) Berkembangnya tren minum kopi di kalangan masyarakat (3) Memiliki kesepakatan dengan pemasok (4) Masih banyak jenis produk kopi yang bisa diproduksi (5) Usahatani kopi semakin diminati.

\section{b. Ancaman (T)}

(1) Persaingan usaha sejenis (2) Kenaikan bahan baku dari pemasok (3) Harga produk substitusi lebih murah dan banyak beredar dipasaran (4) Pembeli beralih ke tempat lain (5) Perubahan pola hidup masyarakat Setelah faktor-faktor srtategi internal dan eksternal diidentifikasi, selanjutnya tabel IFAS (Internal Strategic Factors Analysis Summary) dan EFAS (Eksternal Strategic Factors Analysis Summary), Untuk lebih jelasnya dapat dilihat pada Tabel 2 dan 3.

Tabel 2.Matriks Faktor Strategi Internal IFAS (Internal Strategic Factors Analysis Summary)

\begin{tabular}{|c|c|c|c|c|}
\hline No & $\begin{array}{l}\text { Faktor Internal } \\
\text { Kekuatan }\end{array}$ & Bobot & Rating & Bobot X Rating \\
\hline 1. & Koordinasi internal perusahaan terlaksana dengan baik & 0,07 & 3,00 & 0,21 \\
\hline 2. & Modal sendiri & 0,10 & 4,00 & 0,41 \\
\hline 3. & Lokasi usaha strategis & 0,10 & 3,00 & 0,31 \\
\hline 4. & Harga produk bersaing & 0,10 & 4,00 & 0,28 \\
\hline 5. & Produk mempunyai atribut kemasan & 0,07 & 4,00 & 0,41 \\
\hline 6. & Tenaga kerja disiplin dan memahami tugas & 0,07 & 4,00 & 0,28 \\
\hline \multirow[t]{3}{*}{7.} & Hubungan baik dengan pelanggan & 0,07 & 4,00 & 0,28 \\
\hline & Subtotal & & & 2,17 \\
\hline & $\begin{array}{l}\text { Faktor Internal } \\
\text { Kelemahan }\end{array}$ & & & \\
\hline 1. & Masih menggunakan sistem informasi manajemen manual & 0,07 & 4,00 & 0,28 \\
\hline 2. & Jaringan distribusi yang belum luas & 0,07 & 3,00 & 0,21 \\
\hline 3. & Keterbatasan peralatan pengolahan kopi yang dimiliki & 0,07 & 3,00 & 0,21 \\
\hline 4. & Jenis produk yang dihasilkan masih kurang & 0,07 & 4,00 & 0,28 \\
\hline 5. & Terbatasnya inovasi ilmu pengetahuan dan teknologi & 0,03 & 3,00 & 0,10 \\
\hline 6. & Masih kurangnya jumlah tenaga kerja & 0,03 & 4,00 & 0,14 \\
\hline \multirow[t]{3}{*}{7.} & Kurangnya promosi & 0,07 & 4,00 & 0,28 \\
\hline & Subtotal & & & 1,48 \\
\hline & TOTAL & 1.00 & & 3,66 \\
\hline
\end{tabular}

Sumber : Data Primer (2020) 
Menurut perhitungan pada tabel 2 . Subtotal kekuatan yaitu 2.17 sedangkan subtotal dari kelemahan yaitu 1.48. Hal ini menggambarkan posisi dimana kedai kopi "AI COFFEE" mampu menggunakan kekuatan untuk menutupi kelemahan yang dimilikinya.

Faktor-faktor internal yang menjadi kekuatan yang dominan kedai kopi "AI

Tabel 11.Matriks Faktor Strategi Eksternal EFAS (Eksternal Strategic Factors Analysis Summary)

\begin{tabular}{|c|c|c|c|c|}
\hline No & Peluang & Bobot & Rating & $\begin{array}{c}\text { Bobot X } \\
\text { Rating }\end{array}$ \\
\hline \multirow{2}{*}{$\begin{array}{l}1 . \\
2 .\end{array}$} & \multirow{2}{*}{$\begin{array}{l}\text { Pangsa pasar olahan kopi masih luas } \\
\text { Berkembangnya tren minum kopi di kalangan } \\
\text { masyarakat }\end{array}$} & 0,14 & 4,00 & 0,57 \\
\hline & & 0,14 & 4,00 & 0,57 \\
\hline \multirow{2}{*}{$\begin{array}{l}3 . \\
4 .\end{array}$} & \multirow{2}{*}{$\begin{array}{l}\text { Memiliki kesepakatan dengan pemasok } \\
\text { Masih banyak jenis produk kopi yang bisa } \\
\text { diproduksi }\end{array}$} & 0,10 & 4,00 & 0,38 \\
\hline & & 0,14 & 4,00 & 0,57 \\
\hline \multirow[t]{3}{*}{5.} & Usahatani kopi semakin diminati & 0,10 & 4,00 & 0,38 \\
\hline & Subtotal & & & 2,48 \\
\hline & \multicolumn{3}{|l|}{ Ancaman } & \\
\hline 1. & Persaingan usaha sejenis & 0,14 & 4,00 & 0,57 \\
\hline \multirow{2}{*}{$\begin{array}{l}2 . \\
3 .\end{array}$} & \multirow{2}{*}{$\begin{array}{l}\text { Kenaikan bahan baku dari pemasok } \\
\text { Harga produk substitusi lebih murah dan banyak } \\
\text { beredar dipasaran }\end{array}$} & 0,05 & 1,00 & 0,05 \\
\hline & & 0,05 & 3,00 & 0,14 \\
\hline 4. & Pembeli beralih ke tempat lain & 0,10 & 3,00 & 0,29 \\
\hline \multirow[t]{2}{*}{5.} & Perubahan pola hidup masyarakat & 0,05 & 2,00 & 0,10 \\
\hline & Subtotal & & & 1,14 \\
\hline
\end{tabular}

Berdasarkan tabel 11.Dapat dilihat bahwa peluang yaitu 2.48 dan subtotal ancaman 1.14. Hal ini artinya kedai kopi "AI COFFEE" mampu mengatasi ancaman dengan memanfaatkan peluang.

Faktor-faktor eksternal yang menjadi peluang dominan dari kedai kopi “AI
COFFEE" yaitu modal sendiri dan produk mempunyai atribut kemasan dengan skor 0,41 . Sedangkam kelemahan yang dominan yaitu masih menggunakan sistem informasi manajemen manual, jenis produk yang dihasilkan masih kurang dan kurangnya promosi dengan skor 0,28. 
kopi “AI COFFEE” yaitu persaingan usaha sejenis dengan skor 0,57.

\section{Penentuan Posisi Perusahaan}

Hasil dari IFAS menunjukan kekuatan mempunyi subtotal 2,17 dan kelemahan subtotal 1,48 maka jika dikurangkan hasilnya 0,69. Sedangkan hasil dari EFAS menunjukan peluang mempunyai subtotal 2,48 dan ancaman mempunyai subtotsl 1,14 maka jika dikurangkan hasilnya 1,33. Selanjutnya kedua hasil pengurangan tersebut diletakan pada diagram analisis SWOT. IFAS menjadi sumbu $\mathrm{X}$ sedangkan EFAS menjadi sumbu Y. Pertemuan kedua titik itu yang menggambarkan posisi perusahaan "AI COFFE.Seperti yang terlihat pada gambar 1 .

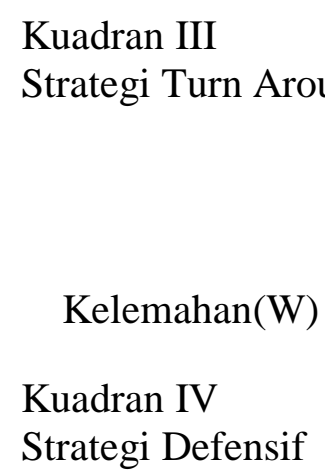

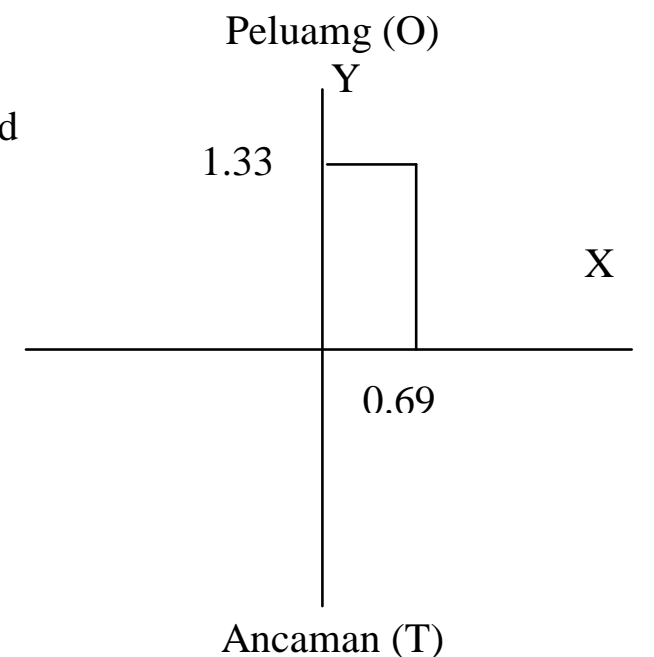

\section{Kuadran I}

Strategi Agresif

Kekuatan( S)

Kuadran

IIStrategi

Difersifikasi

\section{Gambar 1. Diagram analisis SWOT}

Berdasarkan hasil dari perhitungan diagram analisis SWOT menunjukan bahwa posisi perusahaan Kedai Kopi "AI COFFEE" berada pada kuadran I, dimana pada posisi ini sebuah usaha maupun industri memiliki posisi yang kuat dan berpeluang untuk berkembang.

\section{Matriks SWOT}

Dari hasil penelitian di lapangan kemudian dilakukan penetapan 24 faktor penentu yang dijadikan dasar dalam kerangka analisis Matriks SWOT untuk strategi pengembangan bisnis kedai kopi "AI COFFEE" di Desa Pakemitan Kecamatan Ciawi Kabupaten Tasikmalaya dapat dilihat pada Tabel 4. 
Tabel 4. Matriks SWOT Kedai Kopi AI

\begin{tabular}{|c|c|c|}
\hline EFAS & \begin{tabular}{|l} 
Kekuatan (Strength) \\
1. Koordinasi internal \\
perusahaan terlaksana \\
dengan baik \\
2. Modal sendiri \\
3. Lokasi usaha strategis \\
4. Harga produk bersaing \\
5. Produk mempunyai atribut \\
kemasan \\
6. Tenaga kerja disiplin dan \\
memahami tugas masing- \\
masing \\
7. Hubungan baik dengan \\
pelanggan
\end{tabular} & $\begin{array}{l}\text { Kelemahan (Weakness) } \\
\text { 1. Masih menggunakan sistem } \\
\text { informasi manajemen manual } \\
\text { 2. Jaringan distribusi yang belum } \\
\text { luas } \\
\text { 3. Keterbatasan peralatan } \\
\text { pengolahan kopi yang dimiliki } \\
\text { 4. Jenis produk yag dihasilkan } \\
\text { masih kurang } \\
\text { 5. Terbatasnya inovasi ilmu } \\
\text { pengetahuan dan teknologi } \\
\text { 6. Masih kurangnya jumlah } \\
\text { tenaga kerja } \\
\text { 7. Masih kurangnya promosi }\end{array}$ \\
\hline Peluang (Opportunity) & STRATEGI S-O & STRATEGI W-O \\
\hline $\begin{array}{l}\text { 1. Pangsa pasar olahan kopi } \\
\text { masih luas } \\
\text { 2. Berkembangnya tren minum } \\
\text { kopi dikalangan masyarakat } \\
\text { 3. Memiliki kesepakatan } \\
\text { dengan pemasok } \\
\text { 4. Masih banyak jenis produk } \\
\text { kopi arabika yang bisa } \\
\text { diproduksi } \\
\text { 5. Usahatani kopi semakin } \\
\text { diminati }\end{array}$ & $\begin{array}{l}\text { 1. Meningkatkan jumlah } \\
\text { produksi } \\
\text { 2. Mempertahankan harga } \\
\text { produk agar diterima pasar } \\
\text { 3. Menggunakan teknologi } \\
\text { modern dalam hal produksi } \\
\text { dan pemasaran }\end{array}$ & $\begin{array}{l}\text { 1. Menggunakan sistem } \\
\text { informasi manajemen modern } \\
\text { 2. Meningkatkan promosi dan } \\
\text { jaringan distribusi }\end{array}$ \\
\hline Ancaman (Treats) & STRATEGI S-T & STRATEGI W-T \\
\hline $\begin{array}{l}\text { 1. Persaingan usaha sejenis } \\
\text { 2. Kenaikan bahan baku dari } \\
\text { pemasok } \\
\text { 3. Harga produk subtitusi } \\
\text { lebih murah dan banyak } \\
\text { beredar dipasaran } \\
\text { 4. Pembeli beralih ke tempat } \\
\text { lain } \\
\text { 5. Perubahan pola hidup } \\
\text { masyarakat }\end{array}$ & $\begin{array}{l}\text { 1. Memberikan pelayanan } \\
\text { terbaik kepada pelanggan } \\
\text { 2. Mengurangi margin antara } \\
\text { harga jual dan biaya } \\
\text { produksi }\end{array}$ & $\begin{array}{l}\text { 1. Menambahkan mesin dan } \\
\text { peralatan serta jenis produk } \\
\text { agar dapat bersaing dengan } \\
\text { perusahaan sejenis dan } \\
\text { memenuhi permintaan } \\
\text { konsumen }\end{array}$ \\
\hline
\end{tabular}

\section{Dari matriks SWOT diperoleh} beberapa alternatif strategi yang dapat dipertimbangkan, antara lain :

\section{a. Strategi S-O (Strenghts- Opportunity)}

strategi kekuatan-peluang adalah strategi yang menggunakan kekuatan internal untuk memanfaatkan peluang eksternl. 
Berdasarkan hasil matriks SWOT diperoleh strategi yaitu Meningkatkan jumlah produksi, Mempertahankan harga produk agar diterima pasar, Menggunakan teknologi modern dalam hal produksi dan pemasaran.

\section{b. Strategi S-T (Strenghts- Threats)} strategi kekuatan-ancaman adalah strategi untuk mengoptimalkan kekuatan internal yang dimiliki dalam menghindari ancaman.diperoleh strategi Memberikan pelayanan terbaik kepada pelanggan dan Mengurangi margin antara harga jual dan biaya produksi

c. Strategi W-O (WeaknessesOpportunity) strategi kelemahan-peluang adalah strategi untuk meminimalkan kelemahan internal yang ada untuk memanfaatkan peluang ekternal.Berdasarkan hasil matriks SWOT diperoleh strategi yaitu Menggunakan sistem informasi manajemen modern dan Meningkatkan promosi dan jaringan distribusi.

\section{d. Strategi W-T (Weaknesses- Threats)}

strategi kelemahan-ancaman adalah strategi defensif untuk meminimalkan kelemahan internal dan menghindari ancaman eksterna Berdasarkan hasil matriks SWOT diperoleh strategi yaitu Menambah mesin dan peralatan serta jenis produk agar dapat bersaing dengan perusahaan sejenis dan memenuhi permintaan konsumen

\section{KESIMPULAN}

1. Faktor-faktor internal yang menjadi kekuatan yang dominan kedai kopi "AI COFFEE" yaitu modal sendiri dan produk mempunyai atribut kemasan dengan skor 0,41. Sedangkam kelemahan yang dominan yaitu masih menggunakan sistem informasi manajemen manual, jenis produk yang dihasilkan masih kurang dan kurangnya promosi dengan skor 0,28.

2. Faktor-faktor eksternal yang menjadi peluang dominan dari kedai kopi “AI COFFE" yaitu pangsa pasar olahan kopi masih luas, berkembangnya tren minum kopi di kalangan masyarakat dan masih banyak jenis produk kopi yang bisa diproduksi dengan skor 0,57. Sedangkan yang menjadi ancaman dominan kedai kopi "AI COFFEE" yaitu persaingan usaha sejenis dengan skor 0,57.

3. Straegi pengembangan yang tepat untuk pengembangan bisnis "AI COFFE" yaitu Strategi S-O yang diperoleh dari matriks SWOT. 


\section{DAFTAR PUSTAKA}

Arikunto, S. 2006. Prosedur Penelitian Suatu pendekatan Praktek. Rineka Cipta. Jakarta.

Anjayani dan Haryanto. 2009. Geografi SMA XI. Perbit Cempka Putih. Jakarta.

David, F.R, 2004. Manajemen Strategi Terjemah.PT. Indeks Kelompok Gramedia. Jakarta.

Fahmi, Mirza., A. Baihaqi., I. A. Kadir. 2014. Analisis Strategi Pemasaran Kopi Arabika 'Bergendaal Koffie' di Kabupaten Bener Meriah. Jurnal Agrisep. 14 (1): 28-35.

Hayati, Maryani dan Manalu. 2004. Pengetahuan Sosial Geografi SMP. ESIS. Jakarta.

Marta, Ida, Bagus. 2006. Pengantar Studi Demografi. PT Penebar Swadaya. Jakarta.

Nazir, Moh. Ph.D, 2005.Metode Penelitian.Ghalia Indonesia, Bogor.Panggabean, E. 2011. Buku Pintar Kopi.Agro Media Pustaka. Jakarta.

Rahardjo, Pudji. 2012. Panduan Budidaya dan Pengolahan Kopi Arabika dan Robusta. Penebar Swadaya. Jakarta.
Rangkuti, F, 2009. Analisis SWOT Teknik Membedah Kasus Bisnis, Reorientasi, Konsep, Perencanaan Srategis Untuk Menghadapi Abad 21. Cetakan 16.PT. Gramedia Pustaka Utama. Jakarta.

Rika Hariance., Rudi Febriamansyah., dan Faidil Tanjung. 2016. Strategi Pengembangan Agribisnis Kopi Robusta Di Kabupaten Solok. Agrisep Vol. 15 No. 1 Hal: 111-126

Subijanto.2011. Peran Negara Dalam Hubungan Tenaga Kerja Indonesia.Jurnal Pendidikan Dan Kebudayaan (Vol 17 No. 6, 2011), halaman 708.

Sugiyono. 2005. Memahami Penelitian Kualitatif. Bandung: Alfabeta.

Tim Karya Tani Mandiri. 2018. Rahasia Sukses Budidaya Kopi. Bandung Nuansa Aulis.

Zaputra, A., Ismayani., Romano. 2015. Strategi Pengembangan Kluster Perkebunan Kopi dan Tebu untuk Pengembangan Ekonomi Kabupaten Aceh Tengah. Jurnal Agrisep. 16 (2): 38-47. 